\title{
A convergência da revista Atrevida nas redes sociais: novas práticas publicitárias nos meios de comunicação
}

Letícia Salem Herrmann Lima*

Resumo: Este estudo tem por objetivo observar o papel da convergência midiática na construção dos novos hábitos de consumo de informação e mídia dos jovens leitores apropriando-se da utilização das redes sociais. Diante da cultura da digitalização, percebe-se a incidência de veículos tradicionalmente impressos buscarem suporte na plataforma digital para divulgação de seus conteúdos midiáticos, reestruturando a comunicação e as ferramentas publicitárias. O recorte deste estudo será a análise da revista brasileira Atrevida e ferramentas disponibilizadas por ela para a convergência de conteúdos através do site e das redes sociais, enfocando as oportunidades publicitárias existentes. Serão utilizados como principais teóricos Jenkins (2008), que estuda a convergência tecnológica e cultural, Maffesoli (1998), sobre grupos ou tribos sociais, Primo (2008), que aborda a interatividade e a comunicação mediada por computadores, Torres (2009), que sugere práticas publicitárias na internet, e Recuero (2009), pesquisadora das redes sociais.

Palavras-chave: convergência publicitária, interação, redes sociais, meios de comunicação, revista Atrevida.

\section{Introdução}

A utilização da tecnologia nos processos cotidianos mudou o funcionamento tradicional entre emissores e receptores. Atualmente, os receptores interagem com os conteúdos oferecidos e esperam um feedback dos meios de comunicação em relação a sua participação. A comunicação, que era estabelecida apenas por um espaço pequeno destinado a participação da audiência, ganha espaço também através de contatos via $e$-mail, comentários em sites e blogues.

\footnotetext{
* Mestranda do programa de Comunicação e Linguagens da UTP, pesquisadora dos processos das novas mídias, professora universitária da UTP e faculdades OPET e consultora das áreas de comunicação social e marketing (leticia_herrmann@ hotmail.com).
} 
Aos poucos os meios de comunicação tradicionais, como a televisão, o rádio, a revista e os jornais, buscam novas formas de divulgação de seus conteúdos compartilhados com a plataforma online. A maioria dos meios utilizados na comunicação tradicional já disponibiliza sites ou blogs com seus conteúdos como forma de complementação ou até mesmo de divulgação do que será publicado no veículo de origem. Estas exigências, gradativamente, acabam mudando as práticas convencionais da comunicação com a utilização de meios e plataformas convergentes para divulgar um mesmo conteúdo, e a publicidade, por sua vez, segue o mesmo caminho buscando oportunidades diferenciadas de atingir seu público.

Este artigo pretende abordar aspectos de convergência entre conteúdos midiáticos do meio revista e as possíveis mudanças no hábito de consumo de seus leitores. Como recorte deste estudo, optou-se por analisar a revista Atrevida, uma das maiores revista brasileiras em número de exemplares, direcionada ao público jovem feminino, com grande presença de anúncios publicitários publicados tanto em seu website como em seu exemplar impresso. A opção pela revista foi decorrente do interesse em pesquisar um meio de comunicação impresso com periodicidade mensal e, desta forma, averiguar sua estratégia de fidelização do público leitor, uma vez que já não é mais necessário aguardar trinta dias para se obter as informações desejadas; podemos acessar facilmente de forma imediata os conteúdos através da internet.

O estudo inicia-se com a apresentação das teorias sobre convergência, redes sociais e interatividade, seguido da análise de informações do próprio meio revista e das ferramentas disponíveis na internet que de alguma forma complementam o conteúdo da revista impressa possibilitando novos canais de comunicação entre a revista, os leitores e os internautas. A conseqüência desta mudança de comportamento do leitor chama a atenção de anunciantes, que acabam destinando suas ferramentas publicitárias nos meios convergentes.

\section{Redes sociais e sites:}

\section{convergência e interatividade entre leitores e usuários}

Muito se fala de convergência de conteúdo, de tecnologia, de cultura, por isso torna-se necessária uma atenção especial aos impactos causados por esta utilização, ao que realmente podemos aproveitar em termos de conteúdo e ao que o consumidor destes materiais pode usufruir de melhoria nas programações direcionadas ao entretenimento ou a informação. Jenkins (2008) aborda a convergência com as suas multiplicidades de conteúdo de entretenimento defendendo a idéia de compartilhamento das plataformas comunicacionais.

Por convergência refiro-me ao fluxo de conteúdos através de múltiplos suportes midiáticos, à cooperação entre múltiplos mercados midiáticos e ao comportamento migratório dos públicos dos meios de comunicação, que vão a quase qualquer parte em busca das experiências de entretenimento que desejam. (Jenkins, 2008: 27) 
O processo de convergência não é simplesmente a conversão de aparelhos, mas também de conteúdos e suas possibilidades de transformação de costumes que estão dentro do comportamento dos consumidores. "A convergência representa uma transformação cultural, à medida que consumidores são incentivados a procurar novas informações e fazer conexões em meio a conteúdos midiáticos dispersos” (Jenkins, 2008: 28). Percebe-se a importância deste tema pelos movimentos cotidianos ocasionados no comportamento dos indivíduos e abordagens frequentes por diversos autores da área da comunicação. Há enfoques sobre questões da convergência de conteúdos e produtos midiáticos, seja no cinema, na televisão, nos quadrinhos, nos games, nos jornais e nas revistas, como por exemplo a revista Atrevida, que apresenta um site e comunidades em redes sociais.

Para se entender o funcionamento das redes sociais, faz-se necessária a compreensão de sua origem. O conceito de rede vem das ciências exatas e da tecnologia que, neste âmbito, significa as conexões e os nós que interligam os sistemas de computadores. As redes permitem troca de informações entre computadores e usuários, e, através delas, estabeleceram-se possibilidades de relacionamentos virtuais entre pessoas: chamadas de redes sociais. "Uma rede social é definida como um conjunto de dois elementos: atores (pessoas, instituições ou grupos; ou nós da rede) ou suas conexões (interações ou laços sociais)" (Wasserman e Faust, 1994; Degenne e Force, 1999 apud Recuero, 2009: 24).

Outro fator importante sobre redes sociais é a possibilidade de interação entre seus participantes. A comunicação mediada por computadores possibilita, através de suas ferramentas, que seus participantes possam estabelecer diálogos e relacionamentos no mundo virtual. Primo (2008: 61) divide o processo de interação como sendo mútua ou reativa:

(...) interação mútua é aquela caracterizada por relações interdependentes e processos de negociação, em que cada integrante participa da construção inventiva e cooperada da relação, afetando-se mutuamente; já a interação reativa é limitada por reações determinísticas de estímulo e resposta.

Considerando os aspectos teóricos de Primo (2008), pode-se categorizar uma rede social online como pertencente à interação mútua, no qual é possível que seus participantes construam conteúdos e interajam de forma livre, sem a limitação de estímulo e resposta.

O processo de integração entre os indivíduos de uma comunidade depende também do grau de relacionamento que seus membros desenvolvem dentro das redes pertencentes, cujo processo é denominado de laço social. "O laço é a efetiva conexão entre os atores que estão envolvidos nas interações. Ele é o resultado, deste modo, da sedimentação das relações estabelecidas entre agentes" (Recuero, 2009: 38) Com um laço social estabelecido, pode-se ainda mensurar o grau de relação entre os laços firmados. Estes laços podem divergir no que se refere ao grau de envolvimento em relação a cada indivíduo. “A força de um laço é uma combinação (provavelmente linear) da quantidade de 
tempo, intensidade emocional, intimidade (confiança mútua) e serviços recíprocos que caracterizam um laço" (Granovetter apud Recuero, 2009: 41).

$\mathrm{Na}$ constituição da intensidade destes laços, segundo Recuero (2009: 41), podemos dividi-los como sendo "fortes" ou "fracos". Os laços fortes são geralmente estabelecidos pelo grau de intimidade entre as pessoas, pela proximidade, e são mais concretos. Já os fracos são caracterizados por relações sociais superficiais e não possuem caráter de intimidade entre os indivíduos. Estes laços sociais podem ser percebidos dentro das redes sociais, e estas redes, por sua vez, são representadas na plataforma virtual pelos "sites de redes sociais" (SRS). Os SRS são plataformas de relacionamento online que geralmente disponibilizam comunidades virtuais dentro destas redes para debater um determinado tema estabelecido pelos seus membros ou mostrar opiniões e atitudes pessoais. "Sites de redes sociais são os espaços utilizado para a expressão das redes sociais na internet” (Recuero, 2009: 102).

Adaptando as idéias de Recuero (2009) e Primo (2008), percebe-se que a apropriação do meio revista no compartilhamento de seu conteúdo em blogs, sites e redes sociais tem como principal objetivo integrar pessoas através de seus grupos sociais, ou tribos sociais, que, segundo Maffesoli (1998), são representados por indivíduos que possuem características em comum e querem pertencer a grupos sociais específicos. Estes grupos podem representar características específicas identificando seus membros dos demais grupos. Utilizando o exemplo da revista Atrevida, identificamos o perfil de usuário como um grupo de meninas jovens de classe social $\mathrm{AB}$, que buscam informações sobre juventude, estudo, moda e namoro (Ibope, 2010).

\section{Revista e Internet como meios de comunicação integrada}

Dos meios de comunicação tradicionais, a revista é um dos que mais possibilita a segmentação de públicos devido ao grande número de títulos e assuntos. Segundo Tahara (1999), a revista possui como uma de suas principais características credibilidade e possibilidade de adequação de seus conteúdos ao perfil do público desejado. São revistas de moda, saúde, carros, artesanatos, dentre tantos outros temas. Esta oportunidade de escolhas cresce a cada dia, e a possibilidade de novos conteúdos vem sendo criado com o objetivo de conquistar o interesse e a atenção de seus públicos, que se tornam cada vez mais exigentes. Contextualizando a questão da segmentação, hoje no Brasil já possuímos um total de 64 categorias do gênero jornalístico em revista, conforme mostra a Tabela 1 .

Diante destas inúmeras possibilidades, o jornalismo em revista busca novas formas de interatividade com seus leitores assegurando a fidelidade do consumidor. Grande parte das revistas possui uma coluna fixa, a carta do leitor, que tem como objetivo estabelecer um canal de comunicação entre as redações e seus consumidores. Com o surgimento da tecnologia e a rapidez na comunicação, este formato já não é eficiente se utilizado sozinho. Se pensarmos que uma revista tem sua publicação mensal, o leitor teria que esperar pelo menos mais trinta dias para ter uma resposta caso sua carta fosse selecionada. 
Tabela 1. Gêneros jornalísticos em revista (Meio e Mensagem Online)

\begin{tabular}{|c|c|c|}
\hline ADMINISTRAÇÃO E RH & GAME & QUÍMICA E DERIVADOS \\
\hline Adolescente & $\begin{array}{l}\text { Gastronomia, alimento e } \\
\text { bebida }\end{array}$ & Regional \\
\hline Agronegócio & GLS & Religião \\
\hline Arquitectura e decoração & Gráfica, design e embalagem & Revista customizada \\
\hline Arte e cultura & Guia, lista e diretório & Saúde \\
\hline $\begin{array}{l}\text { Associação, Sindicato, Clube e } \\
\text { Colônia }\end{array}$ & Hotelaria & Segurança e trabalho \\
\hline Astrologia e horóscopo & Humor & Série e documentário \\
\hline Automobilismo e motociclismo & Imobiliário & Tecnologia e informática \\
\hline Aviação & Indústria & Telecomunicação \\
\hline Beleza & Infanto-juvenil & Transporte \\
\hline Bem-estar & Informação semanal & \\
\hline Busca & Interesse geral & \\
\hline Celebridade & Joalheria e relojoaria & \\
\hline Ciência e educação & Luxo & \\
\hline Cinema e televisão & Mãe, bebê e casamento & \\
\hline Construção e engenharia & Marketing e propaganda & \\
\hline Costura e trabalhos manuais & Masculino & \\
\hline Direito e tributação & $\begin{array}{l}\text { Mecânica, metalurgia e } \\
\text { mineração }\end{array}$ & \\
\hline Economia e negócio & Medicina e odontologia & \\
\hline Elétrica e eletrônica & Meio ambiente & \\
\hline Entretenimento & Moda & \\
\hline Erotismo & Música & \\
\hline Esportes & Notícia e jornalismo & \\
\hline Feminina & $\begin{array}{l}\text { Operadora de TV por } \\
\text { assinatura }\end{array}$ & \\
\hline Filme & Pesca & \\
\hline Fitness & Petróleo, gás e energia & \\
\hline Foto, ótica e som & Portal de Internet & \\
\hline
\end{tabular}


Visando este e outros motivos, como a própria cultura dos novos leitores, as revistas começaram também a fazer publicações online nos seus sites e blogs. Mas porque tanta transformação? A comunicação está mais rápida e conseqüentemente as pessoas também. Não precisamos esperar o jornal televisivo da noite para saber o que aconteceu durante o dia, já está tudo disponível na internet e o jornalismo das revistas caminha junto à rapidez da informação, principalmente com as possibilidades interativas propiciadas pelas redes sociais.

As redes sociais vêm crescendo cada vez mais em todo o mundo. É através das redes sociais que o consumidor se informa e escolhe seus bens e estilos de vida. O funcionamento das redes sociais, intermediadas por computadores, se dá através das interações e laços sociais que, como mencionado anteriormente, os indivíduos estabelecem durante suas comunicações; e este é um dos principais fatores de interesse de seus usuários. Os laços sociais, segundo Recuero (2008: 40), “(...) são aqueles que se caracterizam pela intimidade, pela proximidade ou pela intencionalidade em criar ou manter uma relação entre duas pessoas".

A internet propiciou a proliferação das redes sociais em todo mundo e os números comprovam que cada vez mais surgem novos adeptos. Em agosto de 2009 o Ibope Nielsen Online, instituto de pesquisa responsável pela aferição da internet e do hábito de consumo dos internautas, tornou público o ranking de audiência na internet brasileira. Divulgou-se a lista dos dez sites mais acessados, incluindo como base de pesquisa residências e local de trabalho. Conforme dados apresentados na Tabela 2, percebe-se que as redes sociais estão no topo da pesquisa perdendo apenas para o Google, tipo de site de busca, e o MSN, disponibilizado para comunicação instantânea.

Tabela 2. Ranking dos dez sites mais acessados no Brasil em agosto de 2009 (IBOPE Nielsen-mm online)

\begin{tabular}{|l|c|c|c|}
\hline \multicolumn{1}{|c|}{ Rand } & Audiência única (000) & Total de minutos (000) & Páginas vistas (000) \\
\hline Google & 34173 & 6394997 & 14893938 \\
\hline MSN/WindowsLive/Bing & 32579 & 14666604 & 4453464 \\
\hline Orkut & 27893 & 6068968 & 18531372 \\
\hline UOL & 27685 & 2797405 & 4075192 \\
\hline Microsoft & 25700 & 1583738 & 159388 \\
\hline IG & 23999 & 1255794 & 2210055 \\
\hline Globo.com & 22918 & 1688541 & 2609028 \\
\hline Terra & 22776 & 1134449 & 1933440 \\
\hline YouTube & 22434 & 1309488 & 1779542 \\
\hline Yahoo & 21871 & 1143352 & 2239515 \\
\hline
\end{tabular}


No Brasil a maior rede social ainda é representada pelo Orkut. Com acesso gratuito, o Brasil mostra-se como representante do maior número de usuários no mundo. A pesquisa realizada pelo Newswire apresentou 21 milhões de visitantes únicos em setembro de 2008, e a diferença para o segundo lugar é considerável, pelo menos cinco vezes menos. Apontou ainda que os visitantes passaram em média 496 minutos no site durante o período de um mês, com média de 28 visitas por visitante, caracterizando-o também como a rede social com maior participação do público. Na Tabela 3, pode-se observar o ranking das visitas e participações das redes sociais no Brasil em setembro de 2008.

Tabela 3. Ranking de visitas nas redes sociais - únicos (000) (World Metrix da comScore) Total Brasil, maiores de 15 anos, acesso de casa ou trabalho

\begin{tabular}{|l|c|c|c|}
\hline SITES SELECIONADOS DE REDES DE RELACIONAMENTO & $\begin{array}{c}\text { TOTAL DE } \\
\text { VISITANTES }\end{array}$ & $\begin{array}{c}\text { MÉDIA DE } \\
\text { MINUTOS }\end{array}$ & $\begin{array}{c}\text { MÉDIA DE } \\
\text { VISITAS }\end{array}$ \\
\hline Total de audiência & 26221 & 1608,10 & 47,5 \\
\hline Orkut & 20752 & 496,1 & 28,3 \\
\hline Yahoo! Geocities & 3916 & 2,8 & 1,8 \\
\hline Sonico.com & 2978 & 10,1 & 2,7 \\
\hline Minglebox.com & 1677 & 1,6 & 2,4 \\
\hline Fotolog.com & 1606 & 22,1 & 5,3 \\
\hline 8P.COM.BR & 1463 & 11,2 & 1,9 \\
\hline Multiply.com & 1189 & 4,4 & 1,5 \\
\hline HI5.COM & 1142 & 10,6 & 2 \\
\hline Lycos Tripod & 1115 & 1,8 & 1,4 \\
\hline Myspace.com & 893 & 13,2 & 2,3 \\
\hline Limeall.com & 387 & 0,6 & 1,7 \\
\hline Deviantart.com & 386 & 7,3 & 1,8 \\
\hline Facebook.com & 360 & 14,2 & 2,7 \\
\hline
\end{tabular}

Este cenário representa as transformações no campo comunicacional impulsionadas pelas possibilidades interativas que a internet propicia, pela convergência dos meios e pelas possibilidades de novas formas de conteúdos e inovações do jornalismo e da publicidade. Grande parte das revistas já transita nestes dois canais, impresso e na rede, e seus leitores estão desenvolvendo o hábito de interagir com ambos.

Além do crescimento da utilização da internet no Brasil, os demais países da América Latina aparecem também como usuários frequentadores das redes sociais. Um estudo realizado pela Insitis Consulting em março de 2010 divulgado na BBC Mundo mos- 
trou que $95 \%$ do total de internautas da América Latina utilizam pelo menos uma rede social. A média mundial de usuários que usam redes sociais representa $72 \%$, com aproximadamente 195 amigos por site. Já na América Latina este número chega a 360 amigos por site, representando quase o dobro da média mundial. No Brasil, como mostra a Tabela 3, o líder absoluto das redes sociais é representado pelo Orkut. Já nos demais países da América Latina, este dado mostra-se divergente, dividindo preferências do próprio Orkut com o Facebook, Twitter, Hi5, MySpace e Sónico, com o acesso variando por país.

O Facebook se mantém como líder de mercado: de seus 400 milhões de perfis, 45 milhões são ativados a partir da América Latina. México, Argentina, Chile e Colômbia concentram o maior número de usuários. Nos Estados Unidos, o Facebook conseguiu ter um tráfego maior que o site do Google. No Brasil, o Orkut reúne mais de 30 milhões de perfis. Os sites MySpace, Hi5 e Sónico disputam posições distintas. O MySpace, segundo dados da Alexa, está em $14 .^{\circ}$ lugar entre os sites mais visitados do México, e no Brasil fica em 98. ${ }^{\circ}$; o Hi5 está em quinto lugar no Peru e no Equador, e em $86 .^{\circ}$ na Venezuela; o Sónico ocupa a $16 .^{a}$ posição na Bolívia, 48. ${ }^{a}$ na Colômbia e 56. ${ }^{a}$ na Argentina. (Cuen, 2010)

Estes dados são importantes para analisarmos a influência das redes sociais em diversos países, principalmente os situados na América Latina. O tema "redes sociais" é discutido em vários eventos da área que prezam o entendimento deste fenômeno da comunicação. O Mídia On, um destes eventos, é realizado anualmente e tem como objetivo debater os rumos das atividades e a tendência da informação no mundo digital. Profissionais da área se reuniram no dia 29 de outubro de 2009 para abordar o tema "Redes sociais podem ser aliadas no jornalismo online", tendo como desafio aos participantes apontar as formas como os jornalistas poderiam interagir com as novas mídias. Dentre inúmeros participantes, o jornalista do IG, Tiago Dória, fez algumas observações sobre o tema e reforçou que "o grande diferencial da internet não é a sua velocidade e sim a sua perenidade”, comentando ainda que os jovens não precisam interagir com as novas mídias, pois já nasceram integrados. Dória ressalta que o advento da tecnologia trouxe a possibilidade de o conteúdo ser produzido até mesmo com a utilização do celular, seja por texto ou imagens.

Outro participante do evento foi o jornalista investigativo José Roberto de Toledo, coordenador da ABRAJI (Associação Brasileira de Jornalismo Investigativo), que deu dicas de como usufruir da melhor maneira das redes como o Twitter e o Facebook. Ele acredita que as duas ferramentas são como um termômetro da sociedade brasileira e considera importante que um jornalista esteja nessas mídias. "O profissional nem precisa se identificar, ou nem mesmo twittar, mas muitas pessoas que são fontes de notícias usam essas ferramentas para divulgar informações que antes não divulgariam” (Midiaon, 2009). Estas informações mostram que os jornalistas já buscam novas formas para se comunicar com o público e demonstram um salto do conservadorismo, se permitindo inovar sem fugir à ética e aos princípios da profissão. 


\section{A revista Atrevida e as convergências midiáticas e de conteúdo: novas práticas na comunicação e na publicidade}

Como pesquisa de observação e exemplo de interatividade do jornalismo com as redes sociais, realizou-se uma análise da revista brasileira Atrevida, da editora Escala. A revista escolhida é direcionada ao público jovem feminino e, além do conteúdo jornalístico do título, disponibiliza um site oficial com links para as redes sociais estimulando o leitor a participar das comunidades envolvidas. A Atrevida possui integração no Orkut, Twitter, blogs, etc.

Atualmente a revista é de circulação mensal e possui uma tiragem de 163000 exemplares. Segundo o IVC (Instituto Verificador de Circulação), o título circula mensalmente uma média de 93572 exemplares entre a revista formato-padrão e a pocket. O título é vendido pelo valor de $\mathrm{R} \$ 4,90$ e atinge na maioria mulheres $(95 \%)$ das classes A (7\%), B (40\%) e C (46\%), entre 15 e 19 anos (38\%) (dados consolidados Ipson Marplan, Janeiro de 2009). Caracterizada pela presença de conteúdo direcionado à jovem brasileira, a revista traz assuntos como amor, relacionamento, sexualidade, beleza, moda, música, ídolos e atualidade. É considerada pelo público como completa, uma das preferidas do segmento. Sua leitora é a adolescente que procura informações sobre as mudanças que estão ocorrendo na sua vida. (Ver Figura 4.)

Com o mesmo perfil e assuntos da revista, a publicação online da Atrevida disponibiliza, além das informações, a possibilidade de interatividade. Apresentando uma média de 2037654 page views mensais, esta publicação representa um número relativamente maior comparado aos dados do meio impresso. A média mensal de visitantes únicos do site em 2009 foi de 188 789. Se compararmos com a circulação das revistas (163 000), sua versão online já ultrapassou o meio impresso (Google Analytics - média mensal 2009). (Ver Figura 5.)

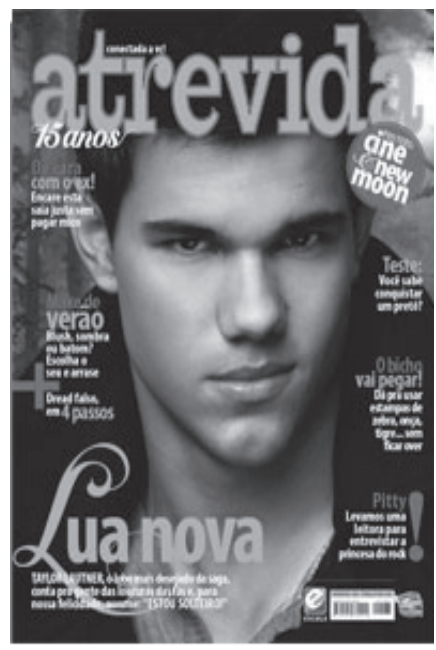

$\triangleleft$ Figura 4. Capa da edição 183 (www.atrevida.com.br)

$\nabla$ Figura 5. Homepage revista Atrevida - presença de redes sociais (www.atrevida.com.br)

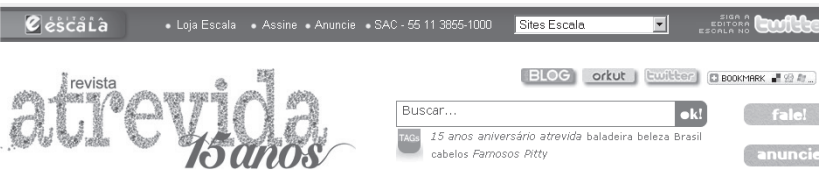


Figura 6. Comunidade oficial da revista Atrevida (www.orkut.com)
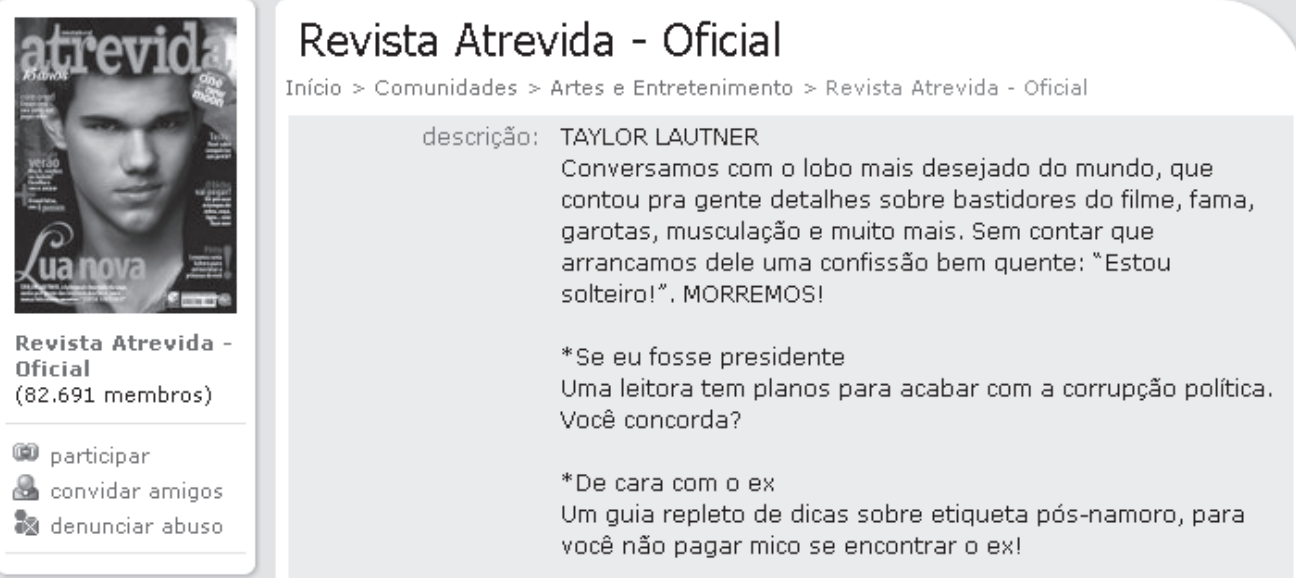

Para fonte de análise das redes sociais, optou-se pelo recorte das comunidades do Orkut, por demonstrar representatividade das redes sociais no Brasil. O levantamento foi realizado entre os dias 8 e 12 de novembro de 2009 e foram encontradas cem comunidades com a tag "Revista + Atrevida". A maior comunidade apresentada, em número de participantes, é a oficial da revista apresentando um total de 82676 membros. (Ver Figura 6.)

Ao analisar o conteúdo da comunidade e da revista, detectou-se que o resumo da edição é atualizado na descrição da comunidade. $\mathrm{O}$ usuário fica por dentro dos assuntos abordados no mês vigente, mesmo não tendo acesso ao exemplar impresso. A publicação na web disponibiliza ferramentas que propiciam a interatividade e a proximidade com o público, envia newsletters e conteúdos para celular, está presente em redes sociais e mantém os esperados testes femininos, transformando-os em enquetes. Santaella (2004: 160) diz que "a comunicação interativa pressupõe que haja necessariamente intercâmbio e mútua influência do emissor e receptor na produção das mensagens transmitidas".

O jornalismo destas publicações é inovador, por permitir interferências em seu conteúdo, incentivando o diálogo com seus consumidores. A grande oportunidade neste mercado é tornar estes consumidores fãs da revista, criando "comunidades da marca", que, segundo Jenkins (2009), são representadas por pessoas que trabalham a favor da marca divulgando os benefícios de seus produtos e serviços gratuitamente. No Twitter a revista já possui 13890 seguidores que se informam sobre os assuntos da revista freqüentemente, e são estes seguidores que representam a movimentação das marcas, que vão divulgar o título. Esta divulgação trabalha com o envolvimento dos usuários, a emoção, gostos e possíveis recomendações em seu ciclo social. Revistas que saíram do impresso, como a Atrevida, apresentam algumas réplicas de conteúdo, uma apropria- 
ção do impresso, diferente das que já nasceram na web e possuem características mais interativas e adaptadas à tecnologia.

Estas mudanças de conteúdo e meios convergentes, juntamente com a mudança estrutural das sociedades proveniente do impulso das redes sociais online, incentivaram também que o mercado publicitário pensasse na possibilidade de outras opções para divulgar seus produtos e serviços.

Os primeiros modelos de publicidade da web foram os banners e os botões que se assemelhavam ao formato impresso tradicional já que apareciam dentro dos contornos claramente definidos. Entretanto, o limitado espaço de banners e botões, aliados a uma (baixa) taxa de clickthought que gira anualmente em torno de $1 \%$ (de acordo com NetRatings [www.netratings.com.br]), inspirou a criação de novos tipos de publicidade na web, que são também mais intrusos. (Zeff, 2000: 25)

Atualmente deparamo-nos com publicidade em blogs, sites, buscadores, programas de conversas instantâneas e redes sociais online. São inúmeras as opções existentes, e a cada dia encontram-se diferentes formas de divulgar produtos e serviços na plataforma virtual possibilitando ainda mais o uso da criatividade publicitária neste meio de comunicação. A internet e suas novas ferramentas auxiliaram na criação de propagandas inovadoras visando à segmentação tão buscada pelos profissionais da mídia ${ }^{2}$. Utilizando redes sociais como fonte de mídia, por exemplo, podem-se selecionar perfis de usuários traçando parâmetros com o perfil do produto oferecido. A publicidade tende a ser dirigida com maior rentabilidade e menor taxa de dispersão, uma vez que comunica com quem deseja ser comunicado sobre um assunto específico.

Os profissionais de marketing procuram moldar a reputação das marcas não através de uma transação individual, mas através da soma total de interações com o cliente - um processo contínuo que cada vez mais ocorre numa série de diferentes 'pontos de contato' midiáticos. (Jenkins, 2009: 96)

A publicidade na internet possibilita formas de comunicação até então não possíveis com intensidade. Atualmente consumidores e empresas trocam informações que visam à satisfação dos clientes e possíveis melhoras dos produtos e serviços oferecidos. A relação entre consumidores e empresas já é propiciada por ferramentas interativas ou experiências sensoriais que auxiliam no processo de decisão de compra na escolha de produtos e serviços. São usados e-mails para os SAC (Sistema de Atendimento ao Consumidor), 0800 (ligação gratuita para a empresa), canal de comunicação online, vitrines virtuais, e-commerce, entre outras possibilidades, buscando tal aproximação.

Devido aos fatores citados acima, a publicidade caminha à possível adaptação ou até mesmo alteração em seu processo constitutivo (Torres, 2009). Com diferentes oportunidades de contato entre a publicidade e seu público, as atuais práticas publicitárias apropriam-se da convergência tecnológica, midiática e cultural para oferecer seus pro-

${ }^{2}$ Profissional responsável pela seleção dos meios de comunicação de uma campanha publicitária. 
dutos onde seu target ${ }^{3}$ tem acesso e costuma freqüentar. $\mathrm{O}$ consumidor da comunicação tem contato com diferentes plataformas comunicacionais e busca referências grupais, observando principalmente as redes sociais online, que preza pela busca constante de informações.

\section{Conclusões}

A revista Atrevida possui um longo percurso para se adaptar completamente ao meio online, considerando que esta seja a opção da editoria; porém, já apresenta novidades tecnológicas aos seus consumidores motivando-os a participarem da cadeia comunicacional do meio com o intuito de fidelização. Dos meios impressos, segundo Tahara (1999), a revista é o meio que mais possibilita o detalhamento dos anúncios devido a sua ótima qualidade de impressão, bela estética visual e fidelização decorrente da segmentação do mercado atuante.

Percebe-se um envolvimento cada vez maior dos jornalistas com os tradicionais meios de comunicação e suas convergências. Não se fala apenas de convergência tecnológica, mas de conteúdos e costumes que convergem. O profissional de comunicação está inserido neste contexto e sabe da tendência a abertura da participação do consumidor nos processos informativos. Se o mais utilizado pelo leitor são as redes sociais, cabe ao profissional apropriar-se do recurso e fazer a melhor utilização possível da ferramenta.

Considerando os dados de crescimento da utilização das redes sociais apresentados neste trabalho e analisando comparativamente a versão impressa e online da revista Atrevida, constatou-se que ocorre uma preocupação por parte dos jornalistas atuantes na revista no que se refere às redes sociais. Se o público está presente nas redes, é lá que os laços comunicacionais precisam ser desenvolvidos. Os números mostraram também como a audiência no meio online vem crescendo, ultrapassando o número de leitores do impresso; é uma mudança comportamental do consumo da informação. Se bem trabalhada, a utilização das redes sociais pode render publicidade gratuita, e a possibilidade de interação entre os consumidores e o veículo representa o pertencimento deste consumidor ao meio, que o fideliza e faz com que as idéias das marcas sejam propagadas de forma rápida e eficiente.

A convergência dos conteúdos e a possibilidade da participação dos usuários nos produtos midiáticos auxiliam no processo de unificação dos meios online e offline fazendo com que a informação seja desenvolvida de forma casada. Este fato proporciona a imersão dos usuários nos meios de comunicação, permitindo que transitem facilmente entre as plataformas. Com a propagação e popularização da internet, com o acesso a todos sem distinção social, será possível integrar ainda mais usuários e leitores e suas plataformas comunicacionais de informação e entretenimento, e o desafio maior será encontrar a dosagem certa nas informações transmitidas em cada meio de comunicação.

Esta nova prática da comunicação apresentada neste artigo mostra uma possível reestruturação dos conteúdos nos meios de comunicação, propiciando a criação de novos 
códigos e políticas comunicacionais em âmbito mundial. Neste exemplo, a mudança foi em relação ao próprio leitor, que se transformou em usuário de redes sociais e do meio revista, e que aproveitou seu conteúdo com a divulgação na internet; mas também em relação aos próprios jornalistas, que se adaptaram à convergência e às novas formas de se fazer comunicação na contemporaneidade.

Constata-se, desta forma, que a publicidade na internet caminha na mesma linha do jornalismo, onde a interferência da informação influencia diretamente a composição publicitária necessária para atingir o público nas campanhas veiculadas. Se o consumidor produz conteúdos e interage nas diferentes plataformas que convergem, é neste ponto que a publicidade deve atuar, fazendo com que suas campanhas, além de estarem presentes nas mesmas plataformas convergentes, ainda propiciem interatividade e experimentação entre os usuários e as marcas.

\section{Referências}

COEN, D. (2010) 'BBC Mundo. América Latina, líder en redes sociales’. Disponível em: http://www.bbc.co.uk/ blogs/mundo/un_mundo_feliz/2010/03/america_latina_lider_en_redes.html>. Acesso em 20/08/2010.

ESCALA. Disponível em: <http://www.escala.com.br/midiakit/detalhe.asp?revista=4>. Acesso em 10/11/09.

IBOPE (2009). Disponível em: <www.ibope.com.br>. Acesso em: 10/09/09.

JENKINS, H. (2008) Cultura da Convergência, São Paulo: Editora Aleph.

MAFFESOLI, M. (1998) O Tempo das Tribos. O Declínio do Individualismo nas Sociedades de Massa, São Paulo: Forensi Universitari.

MÍDIAON (2009). Disponível em: <http://www.mmonline.com.br/noticias.mm?url=Media_ On_2\&origem=mmbymail. Acesso em: 01/11/09.

MMONLINE. 'Anuário de Mídia Revistas'. Disponível em: <www.mmonline.com.br>. Acesso em: 10/11/09.

MMONLINE. 'Ibope Nielsen aponta sites de maior audiência'. Disponível em: <http://www.meioemensagem. com.br/novomm/br/Conteudo/?Ibope_Nielsen_aponta_sites_de_maior_audiencia >. Acesso em: 21/09/09.

MORA, D. (2009) 'Redes Sociais avançam na América Latina'. Disponível em: <http://knightcenter.utexas. edu/blog/?q=pt-br/node/6856>. Acesso em: 20/08/2010.

NATANSOHN, G., PARANHOS, V. (2009) 'A interatividade no jornalismo de revista: o caso da revista Muito, do grupo A Tarde’. Disponível em: <http://www.intercom.org.br/papers/regionais/nordeste2009/ resumos/R15-0391-1.pdf>. Acesso em 10/11/09.

NATANSOHN, G., SILVA, T., BARROS, S. (2009) 'Revistas Online: cartografia de um território em transformação permanente'. Disponível em: <http://www.slideshare.net/tarushijio/revistas-online-cartografia-de-um-territorio-em-transformacao-permanente>. Acesso em 30/10/2009.

ORKUT. Disponível em: <www.orkut.com.br>. Acesso em: 12/11/09.

PRIMO, A. (2008) Interação Mediada por Computador. Comunicação, Cibercultura, Cognição, Porto Alegre: Sulina.

PRNEWSWIRE. 'Pesquisa sobre as Redes Sociais e o Orkut'. Disponível em: <http://www.prnewswire.com. br/news/081100000307.htm>. Acesso em: 20/10/09.

RECUERO, R. (2009) Redes Sociais na Internet, Porto Alegre: Sulina.

REVISTA ATREVIDA. Disponível em: <http://atrevida.uol.com.br/>. Acesso em 10/11/09.

SANTAELLA, L. (2004) 'Navegar no ciberespaço. O perfil Cognitivo do Leitor Imersivo', São Paulo: Paulus, pp. $151-172$.

TAHARA, M. (1999) Contato Imediato com Mídia, São Paulo: Global Editora.

TORRES, C. (2009) A Bíblia do Marketing Digital: Tudo o que você queria saber sobre marketing e publicidade na internet e não tinha a quem perguntar, São Paulo: Novatec Editora.

ZEFF, R. (2000), Publicidade na Internet, São Paulo: Editora Campus. 